\title{
Nutritional supplement practices in UK junior national track and field athletes
}

\section{A Nieper}

Correspondence to:

Alex Nieper, UK Athletics, Crystal Palace, Ledrington Road, Norwood, SE19

2BB, UK; alex.nieper@ eis2win.co.uk

Accepted

21 December 2004

\begin{abstract}
Methods: The nutritional supplementation practices of 32 national track and field athletes competing at the 2004 World Junior Championships were studied using an anonymous questionnaire. Information was sought on the prevalence and type of supplement used, the reasons for use, knowledge of supplements, and sources of information.

Results: Use of supplements was widespread with $62 \%$ of respondents declaring supplement use. Prevalence in female athletes $(75 \%)$ was higher than in males $(55 \%)$ but was not statistically significant. No differences were found for age, training volume, or type of event. Seventeen different supplements were taken, with each athlete using an average of 2.4 products, multivitamins and minerals being the most popular. Reasons for using supplements were for health (45\%), to enhance the immune system (40\%), and to improve performance (25\%). Of all respondents $48 \%$ believed they had an average knowledge of supplements, but three quarters felt that they required further information. Those not using supplements were more likely to think supplements were associated with health risks than those taking them $(p=0.03)$. Most athletes (72\%) have access to a sports dietician but underutilise this resource. Coaches $(65 \%)$ had the greatest influence on supplementation practices, with doctors $(25 \%)$ and sports dieticians $(30 \%)$ being less important.

Conclusions: Supplementation practices were widespread among the population studied. The findings of this investigation could be used to enable the sports dietician and physician to identify common misconceptions held by adolescent athletes regarding nutritional supplements and to implement educational programs, which should include members of the non-medical support team.
\end{abstract}

A thletes have used various substances for their ergogenic benefits since ancient times and many use nutritional supplements without consideration of possible negative consequences. The International Olympic Committee (IOC) prohibits many chemical and hormonal substances that offer an unfair advantage to the user. ${ }^{1}$ Nutritional supplementation, however, is a grey area and as more drugs are placed on the banned list for athletes, supplements and herbal preparations have gained popularity as a way to achieve performance enhancement "legally".

Despite lack of scientific evidence to support their alleged benefits, ${ }^{2-4}$ the retail sale of dietary supplements in the USA generated $\$ 3.3$ billion in 1990 and $\$ 13.9$ billion in 1998, and is predicted to triple by the end of $2005 .{ }^{5}{ }^{6}$ Unlike medicines, there is no governing body to control and regulate the supplement industry. In the USA, the Food and Drug Administration formerly protected the public from mislabelled and unsafe dietary supplements and herbal preparations but lost its regulatory powers with the Dietary Supplement and Health Education Act of 1994, and can now only take action after adverse health effects have occurred..$^{78}$ In Europe, regulations have been drafted at national and European level ${ }^{9}{ }^{10}$ and will be enforced from the end of 2005 in the UK. Unless scientific evidence is strong, displays of health claims are unlikely to be allowed on the product label.

Regulations in other nations are not as stringent and athletes, therefore, remain vulnerable. There is also a small but real risk of an athlete committing an unintentional doping offence as the result of ingesting a dietary supplement or herbal preparation since the IOC list of doping substances includes several which occur naturally in nutritional supplements. ${ }^{1-13}$ The IOC acknowledge the situation and have softened their rules to state that "unintentional anti-doping rule violations... may result in reduced sanctions".

Athletes are also at risk of significant adverse effects as some dietary supplements and herbal preparations have been associated with cardiovascular, neurological, metabolic, and haematological problems. ${ }^{14-16}$ Governing bodies, such as UK Sport $^{17}$ and the British Olympic Association, ${ }^{18}$ warn athletes about these risks on their web pages.

In the UK, the supplementation practices of athletes remain relatively unknown and it is, therefore, difficult to decide if findings from overseas studies are applicable here. Because of the risks associated with supplement use outlined above, it was considered important to gather basic data on the prevalence and type of supplement used and also the reasons, knowledge levels, and influences which aid the athletes in their decision. Elite athletes are more likely to be under pressure to take supplements and it was, therefore, decided to study this population.

The objectives of this study were to determine: (a) the prevalence and type of supplements used by the current national junior track and field squad; (b) the frequency and reasons for the use of supplements; (c) knowledge and sources of supplement information; and (d) if gender, age, sporting event, or training load influence supplement use.

\section{METHODS}

\section{Study population}

All 34 male and female track and field athletes selected for the Great Britain junior team and participating at the IAAF 2004 World Junior Championships were targeted for this study. The objectives and requirements of the study were explained and written consent was obtained from all athletes. No ethical approval was necessary, but the medical 
Table 1 Characteristics of the athletes

\begin{tabular}{lllc}
\hline & Number & $\begin{array}{l}\text { Age, years } \\
\text { (mean) }\end{array}$ & $\begin{array}{l}\text { Training per } \\
\text { week, hours } \\
\text { (mean } \pm \text { SD) }\end{array}$ \\
\hline All athletes & 32 & 18 & $9.7 \pm 4$ \\
Females & 12 & 18 & $10.2 \pm 5$ \\
Males & 20 & 18 & $9.4 \pm 3.5$ \\
\hline SD, standard deviation. & & \\
\hline
\end{tabular}

commission of the national governing body, UK Athletics, was informed about the procedure and aims of the study. The contact details of the researcher were provided allowing any queries to be addressed immediately. A questionnaire about nutritional supplementation practices was sent, with other registration material, by post to the athletes by the World Junior Championships UK administrators. Approximately 2 weeks were allowed for completion and return of the anonymous questionnaires. No attempt was made to follow up the non-responders.

\section{Questionnaire}

The questionnaire was designed to provide data on supplementation patterns, knowledge, and resources in the study population. A draft of the questionnaire was first given to six independent athletes who attended the Crystal Palace sports centre for medical treatment. Feedback was specifically sought on language and content. Two independent sports physicians and a sport nutritionist then critiqued the final draft. The term "nutritional supplement" was not defined for the athletes. In the data analyses, however, supplements were defined as "ergogenic aids" (creatine, caffeine) or "recovery nutrients" (vitamins/minerals, glucosamine, glutamine). A Likert scale (range 1-5) was used to estimate knowledge ( 1 , poor; 3 , average; 5 , excellent) and frequency ( 1 , occasional; 3, weekly; 5 , daily) of supplement use, as well as access to sport dieticians ( 1 , not at all; 3 , monthly; 5 , weekly).

\section{Statistical methods}

Statistical analysis was performed using the Stata 6.0 software package. A p value $<0.05$ was considered statistically significant. Statistical analyses were also performed to compare subjects taking and not taking supplements. Variables measured on a continuous scale were compared between groups using a $t$ test. Categorical variables were compared using Fisher's exact test. This test was used in preference to the $\chi^{2}$ test, which does not work well with small numbers of subjects as in this study. Descriptive data were calculated as frequencies (\%) and are represented as the mean \pm standard deviation. Analyses were calculated for all subjects combined and also separately by gender.

\section{RESULTS}

\section{Demographic characteristics}

A total of 32 questionnaires were received and analysed, a response rate of $94 \%$. The characteristics of the athletes are given in table 1.

Reported prevalence and frequency of supplement use Frequency of supplement use and number of products taken are given in table 2 . Overall, $62 \%$ of athletes supplemented their diet $(75 \%$ of females and $55 \%$ of males, $\mathrm{p}=0.45)$.

Age $(p=0.52)$, training volume $(p=0.81)$, and type of event $(p=0.46)$ did not have an influence on supplement usage.

Respondents took a total of 17 different supplements with each athlete using an average of $2.4 \pm 1.5$ different products. Supplements were taken on a daily basis by $50 \%$ of respondents. Multivitamins were the most frequently used supplement $(45 \%)$, followed by individual vitamin C (35\%) and iron $(30 \%)$.

\section{Reason for supplement use}

Figures 1 and 2 show the reasons given by the athletes regarding their decision to use or not use supplements.

\section{Knowledge and resources}

Most athletes had been recommended to use supplements by their coach (67\% female and 64\% male), while parents were also very influential ( $44 \%$ and $36 \%$, respectively). Most of the athletes $(58 \%)$ checked with the medical team before taking supplements and the majority obtained their supplements from health food shops (53\%) or supermarkets (29\%).

Self reported supplement knowledge scores were broken down into those who did and did not take supplements (fig 3). Forty eight per cent of all respondents believed they had an average knowledge of supplements, but most (75\%)

Table 3 Opinions on supplements

\begin{tabular}{|c|c|c|c|}
\hline & No supplement & Supplement & \\
\hline & n (\%) & n (\%) & $\mathrm{p}$ value \\
\hline $\begin{array}{l}\text { Supplements enhance } \\
\text { performance }\end{array}$ & $7(63)$ & $11(58)$ & 1.00 \\
\hline $\begin{array}{l}\text { Exercise increases the } \\
\text { need for supplements }\end{array}$ & $2(18)$ & $15(83)$ & 0.001 \\
\hline $\begin{array}{l}\text { Supplements are } \\
\text { associated with } \\
\text { health risks }\end{array}$ & $10(83)$ & $8(42)$ & 0.03 \\
\hline $\begin{array}{l}\text { Supplements can } \\
\text { cause a positive } \\
\text { doping test result }\end{array}$ & $11(92)$ & $12(71)$ & 0.35 \\
\hline $\begin{array}{l}\text { Not needed if have } \\
\text { a balanced diet } \\
\text { Would like to get more }\end{array}$ & $11(91)$ & $17(85)$ & 1.00 \\
\hline advice on supplements & $5(50)$ & $16(89)$ & 0.06 \\
\hline
\end{tabular}

Table 2 Supplement use

\begin{tabular}{|c|c|c|c|c|c|c|c|c|}
\hline & \multicolumn{2}{|c|}{ Supplement use (\%) } & \multicolumn{5}{|c|}{ Frequency of use, Likert scale $(\%)^{*}$} & \multirow{2}{*}{$\begin{array}{l}\text { Supplements, } \\
\text { number } \pm \text { SD }\end{array}$} \\
\hline & Yes & No & 1 & 2 & 3 & 4 & 5 & \\
\hline All athletes (\%) & $20(62)$ & $12(38)$ & $4(22)$ & $2(11)$ & 0 & $3(17)$ & $9(50)$ & $2.4 \pm 1.5$ \\
\hline Females (\%) & $9(75)$ & $3(25)$ & $1(13)$ & 0 & 0 & $1(13)$ & $6(75)$ & $2.3 \pm 1.5$ \\
\hline Males (\%) & 11 (55) & $9(45)$ & $3(30)$ & $2(20)$ & 0 & $2(20)$ & $3(30)$ & $2.4 \pm 1.5$ \\
\hline
\end{tabular}

*Scale: 1, occasional use; 5 , daily use.

$\mathrm{SD}$, standard deviation. 


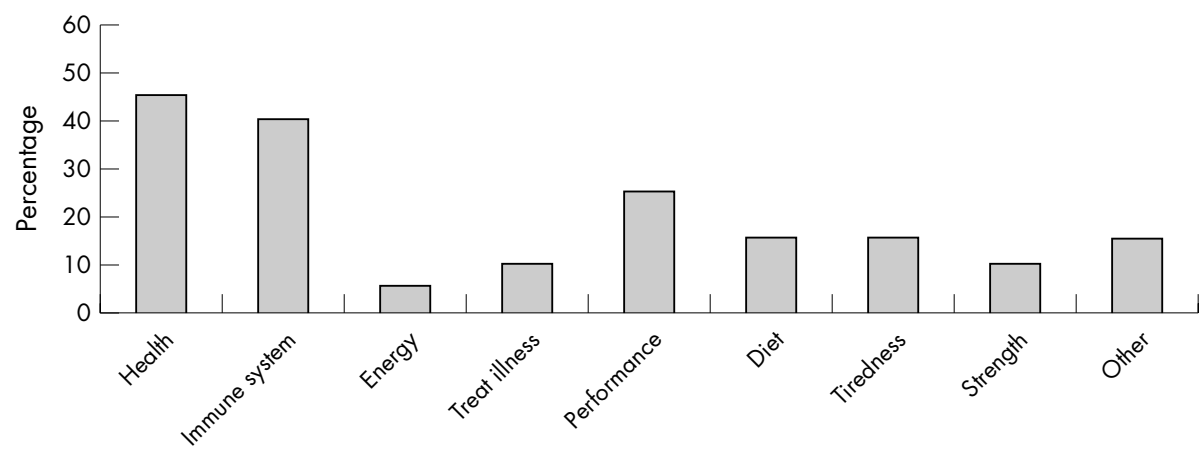

Figure 1 Why do you take supplements?

felt that they required further advice and/or information on nutritional supplements. Some evidence of difference was found between those taking supplements (89\%) and those not taking supplements $(50 \%)$ as to whether more advice on supplements was required, although this result was only of borderline statistical significance $(p=0.06)$. No respondent felt they had an excellent knowledge level.

\section{Doping and health risks}

Athletes were asked their opinion on a range of dietary, performance, and health related issues. Those who answered affirmatively to the questions were then separated into those who took supplements and those who did not (table 3 ).

Of the subjects not taking supplements, $83 \%$ believed they could be harmful compared to only $42 \%$ of those who took supplements. Athletes who took supplements were also more likely to believe that exercise increases the need for supplements $(83 \%$ compared to $18 \%$ ). Those not taking supplements were more likely to think that supplements could lead to a positive doping test result than those who were taking supplements, although this difference was not found to be statistically significant.

There was no difference between the groups in their access to a dietician (supplements $75 \%$, no supplements $67 \%$, $\mathrm{p}=0.70)$ or their consultation rate $(70 \% v 67 \%, \mathrm{p}=1.00)$.

\section{DISCUSSION}

\section{Prevalence of supplement use}

Nutritional supplementation was widespread amongst this group of elite junior track and field athletes. The overall figure of $62 \%$ was similar to that calculated by the author in a recent literature review looking at supplementation studies from the past 10 years. ${ }^{19}$

The prevalence was slightly higher for female $(75 \%)$ than male athletes $(55 \%)$, although this did not reach statistical significance $(p=0.45)$. The trend was similar to that observed in previous studies ${ }^{20} 21$ and possible explanations include females being more susceptibility to advertising, more aware of nutritional needs, and having more real need for supplements (for example, ferrous sulphate due to menstrual loss) compared to male athletes.

Prevalence was not influenced by age, sporting event, or training volume in this study, but this should be viewed critically due to the small range of ages and events participated in by this population.

\section{Type, frequency, and reason for supplement use}

Respondents supplemented their diet with an average of 2.4 different products, usually on a daily basis. These findings are similar to those of Slater and Tan.22 It is of note, however, that the study was conducted during peak activity and results might be different during the off season. Athletes were also asked to consider only the past 3 months when estimating their supplement use. The majority (95\%) of those using supplements denied taking them more frequently when training intensity increased even though $83 \%$ thought that exercise increased the need for supplements. This contradiction between belief and practice needs to be further explored.

The most popular supplements taken by female athletes were the "recovery nutrients" (44\%). This might be explained by the finding that many female athletes are restrictive eaters and do not want to add extra energy to their diet. This is supported by the primary motivations cited for taking supplements: health issues (33\%) and strengthening the immune system (44\%). Performance and strength (both $11 \%)$ were perceived as less important.

Male athletes used "ergogenic aids" more often than the female athletes $(45 \% \vee 11 \%)$, but no statistical significance was reached. This is in accordance with the studies of Sundgot-Borgen $e t$ al $^{19}$ and Slater and $\operatorname{Tan}^{22}$ and is supported by the fact one of the main reasons reported by males for

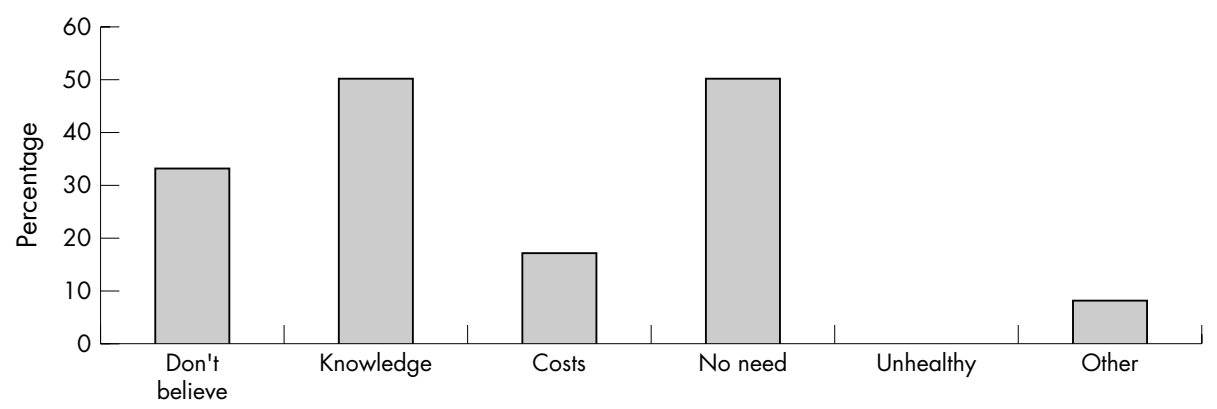

Figure 2 Why do you not take supplements? 


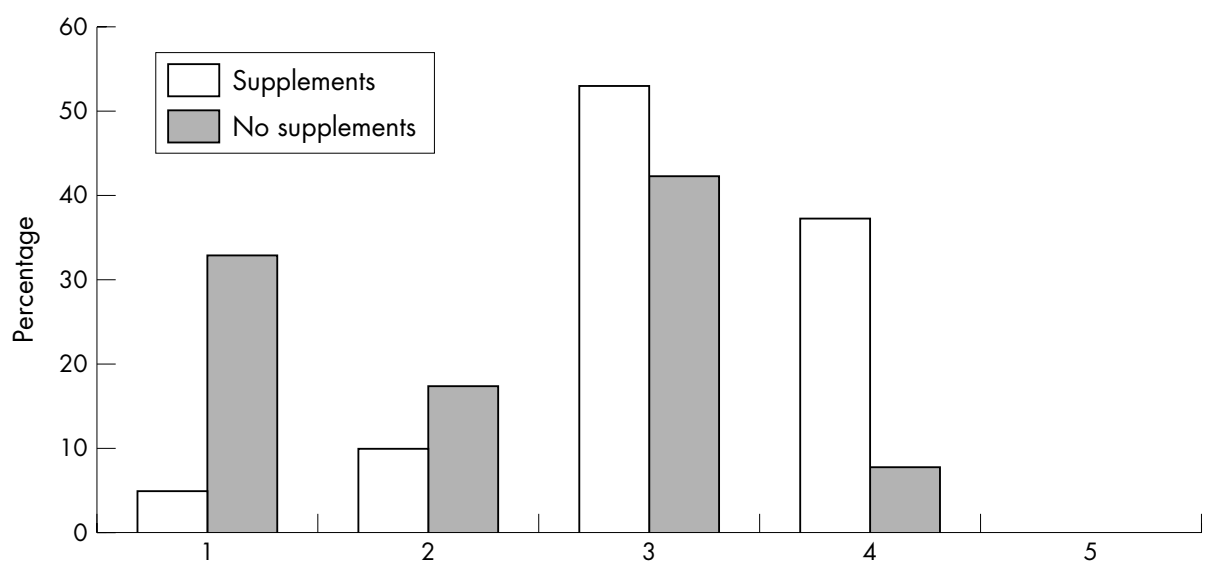

Figure 3 Knowledge scores. Scale: 1, poor knowledge; 5, excellent knowledge.

taking supplements is to improve performance (36\%). Although some studies suggest that some supplements, such as caffeine, creatine, and sodium bicarbonate, have ergogenic potential, these supplements may have side effects and their applicability is limited to certain types of exercises and individuals. ${ }^{4}$ The low prevalence of creatine use reported in this study $(18 \%)$ is therefore understandable as creatine causes instance weight gain, which can impair performance. Interestingly, two male athletes reported the use of iron supplements to treat symptoms of fatigue and tiredness. Iron supplementation is unlikely to be required by men and if taken excessively can have negative health consequences. ${ }^{3}$

It is important to note that no dietary evaluation of the athletes was undertaken and therefore it is not known whether some of these athletes were nutritionally deficient, although $85 \%$ of athletes supplementing considered their diet to be well balanced. To date there is no conclusive scientific evidence supporting the use of nutritional supplements in a healthy athlete eating a well balanced diet, but adverse effects are likely if supplements are taken in large amounts. ${ }^{34}$

The most frequent reasons for not taking supplements were lack of knowledge and no need for supplements (both 50\%). Costs were less important $(17 \%)$, reflecting the trend that people are increasingly willing to pay for products with alleged benefits. ${ }^{23}$

It is of great concern to the author that only one athlete in this study was worried about supplement purity and safety and only $71 \%$ of those supplementing believed that this could lead to a positive doping test as opposed to $94 \%$ not supplementing. The risk of committing a doping offence is small but real and needs to be a core topic when planning educational programs for athletes. ${ }^{11-13}$

\section{Knowledge of supplements}

Knowledge may be an important factor in reducing nutritional supplement use. Massad et $a^{24}$ reported an inverse relationship between the knowledge and use, but this was not supported by the findings of the present study. Athletes who supplemented their diet reported greater knowledge levels (mean Likert score 3.2) than those who did not (2.6). This is most likely explained by the fact that athletes were asked about their own perception of supplement knowledge, while other investigations have assessed nutritional knowledge. $^{24}{ }^{25}$ The validity of the knowledge scores must, therefore, be questioned, but the scores do provide an interesting insight into the perceived awareness of these teenage athletes and possible over-confidence in their own decision making abilities.

\section{Influence on supplement use and sources of information}

More than $75 \%$ of the athletes had access to a sports dietician, but the majority used this service infrequently. This supports the findings of Rockwell et al who also reported an underutilisation of nutritional professionals. ${ }^{26}$ Dietary assessment is currently not compulsory for national junior athletes in the UK but does provide an opportunity for counselling and nutrition education. Dieticians working in high performance centres need to promote their availability to ensure that coaches and athletes are informed about their services. Routine entry physical examinations may also allow sports physicians to open discussions about nutrition and supplements.

Coaches had the greatest influence on athletes' supplementation practices, with doctors $(25 \%)$ and sports dieticians (30\%) seen as less influential. This supports previous findings that athletes rely on information sources where accuracy cannot be guaranteed. ${ }^{22}$ Coaches have no compulsory nutritional education and it has been shown that they lack appropriate knowledge. ${ }^{26}$ It is suggested that any nutritional education programs should include coaches, as athletes may be reluctant to change their habits unless supported by their coach.

It is of concern is that only two athletes received their supplements from the medical support team, whereas the others bought from sources where purity and safety cannot be guaranteed, such as health shops and the Internet.

\section{Limitations of the study}

The main limitation was the small size of the study population and, as a result, there was a relatively low power to detect differences between the groups. The subjects were competing in a major event and may have been using supplements more than usual. The questionnaire was also included with other registration documents for the World Junior Championships and, although this probably improved return rates, participants may have been concerned about confidentiality.

Future research in this area needs to consider supplement use over a longer period in order to provide more information on patterns and trends. A larger population including a wider range of ages and sporting events would also address some of the limitations of this study.

\section{CONCLUSION}

Supplementation practices were widespread among the population studied. The findings of this study could be used to enable the sports dietician and physician (a) identify 


\section{What is already known on this topic}

Many athletes use nutritional supplements without consideration of possible negative consequences. In the UK, the supplementation practices of athletes remain relatively unknown.

\section{What this study adds}

Over half the members of a national track and field adolescent squad took nutritional supplements. More female than male athletes took supplements.

common misconceptions held by adolescent athletes regarding nutritional supplements and (b) implement educational programmes, which need to include members of the nonmedical support team. An honest discussion of the limitations of most supplements, and acknowledgement that some supplements may work in certain athletes, may lead the sports physician and dietician to be more credible and useful to the athlete in providing medical care and guidance that supports the desire to improve performance.

\section{ACKNOWLEDGEMENTS}

The author would like to thank the athletes, UK Athletics, and the team management of the UK National Junior Track and Field squad.

Competing interests: none declared

\section{REFERENCES}

1 International Olympic Committee. http://www.olympic.org/uk/ index_uk.asp (accessed 23 May 2005).

2 Singh A, Moses FM, Deuster PA. Chronic multivitamin-mineral supplementation does not enhance physical performance. Med Sci Sports Exerc 1992;24:726-32.

3 Schwenk TL, Costley CD. When food becomes a drug: nonanabolic nutritional supplement use in athletes. Am J Sports Med 2002;30(6):907-16.

4 Juhn MS. Popular sports supplements and ergogenic aids. Sports Med 2003;33(12):921-39.

5 US Food and Drug Administration. Dietary supplements. http:// www.cfsan.fda.gov/ dms/supplmnt.html (accessed 23 May 2005).
6 USDA Food Surveys Research Group. Supplementary data tables. USDA's 1994-1996 continuing survey of food intake by individuals. http:// www.barc.usda.gov/bhnrc/foodsurvey/pdf/Supp.pdf /accessed 23 May 2005).

7 Hathcock J. Dietary supplements: how they are used and regulated. J Nutr 2001;131(3):1114-7S.

8 US Food and Drug Administration. Dietary Supplementation Health and Education Act of 1994. Public Law 103-417, 103rd Congress. http:// www.fda.gov/opacom/laws/dshea.html (accessed 23 May 2005).

9 Health Food Manufacturers' Association. Food supplement regulations published. Thames Ditton, Surrey, UK: HFMA Labelling, Advertising and Promotion Advice Division, 2003;4(1):1-6.

10 Scientific Committee On Food. Report on composition and specification of food intended to meet the expenditure of intense muscular effort, especially for sportsmen. Brussels: European Commission, 2001:1-50.

11 Geyer H, Parr MK, Mareck U. Analysis of non-hormonal nutritional supplements for anabolic-androgenic steroids - results of an international study. Int J Sports Med 2004;25(2):124-9.

12 Geyer H, Mareck-Engelke U, Reinhart U. Positive doping cases with norandrosterone after application of contaminated nutritional supplements. Disch Z Sportmed 2000;51(11):378-82.

13 Baylis A, Cameron-Smith D, Burke LM. Inadvertent doping through supplement use by athletes: assessment and management of the risk in Australia. Int J Sport Nutr Exerc Metab 2001;11(3):365-83.

14 Scally MC, Hodge A. A report of hypothyroidism induced by an over-thecounter fat loss supplement (Tiratricol). Int J Sport Nutr Exerc Metab 2003;13(1):112-6.

15 Foxford RJ, Sahlas DJ, Wingfield, KA. Vasospasm-induced stroke in a varsity athlete secondary to ephedrine ingestion. Clin J Sports Med 2003; 13:183-5.

16 Palmer ME, Haller C, McKinney PE, et al. Adverse events associated with dietary supplements: an observational study. Lancet 2003;11:101-6.

17 UK Sport. http://www.uksport.gov.uk (accessed 23 May 2005).

18 British Olympic Association. http://www.boa.org.uk (accessed 23 May 2005).

19 Sundgot-Borgen J, Berglund B, Torstveit MK. Nutritional supplements in Norwegian elite athletes - impact of international ranking and advisors. Scand J Med Sci Sports 2003;13:138-44.

20 Ziegler PJ, Nelson JA, Jonnalagadda SS. Use of dietary supplements by elite figure skaters. Int J Sport Nutr Exerc Metab 2003;13:266-76.

21 Sobal J, Marquart LF. Vitamin/mineral supplement use among athletes: a review of the literature. Int J Sport Nutr 1994;4:320-34.

22 Slater G, Tan B. Dietary supplementation practices of Singaporean athletes. Int J Sport Nutr 2003;13:320-32.

23 Anonymous. Use of herbal supplements increases $350 \%$ in three years. Health Med Week 2001; June 11:8-9.

24 Massad SJ, Shier NW, Koceja DM, et al. High school athletes and nutritional supplements: a study of knowledge and use. Int J Sport Nutr 1995;5:232-45.

25 Kay NS, Shier N, Ding K, et al. Nutritional supplements and uses by college students in U.S.A., Thailand and Republic of China (Taiwan). Dtsch Z Sportmed 2002;38(2):51-5

26 Rockwell MS, Nickols-Richardson SM, Thye FW. Nutrition knowledge, opinions, and practices of coaches and athletic trainers at a division I university. Int $J$ Sport Nutr 2001;1 1:174-85 